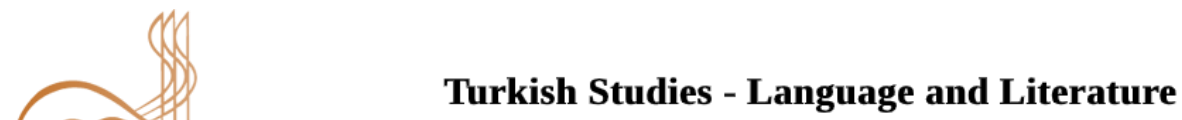

www.turkishstudies.net/language

eISSN: 2667-5641

BALKAN

Research Article / Araştırma Makalesi

Sponsored by IBU

\title{
Rus Yeradbiliminde Geliştirilen İnceleme Yöntemleri ve Rus Toponimlerinde Uygulanabilirliği*
}

Research Methods Developed in Russian Toponymy and Their Applicability

Sonnur Aktay ${ }^{* *}$

\begin{abstract}
The places of names have always been a matter of interest for researchers since the ancient times. As the societies became more and more interested in the places where they live, this situation led the researchers to do studies on the origin, etymology, meaning and history of the names of the places as well as their connection with other societies. The place names represent the history, lifestyle and culture of societies, so every feature related to names required special field for place names. In Russia, it is known that the interest in toponymy began in the ancient times; however, academic studies only began to be conducted in 18th and 19th centuries. During that times, in order to conduct these studies systematically, certain research methods were developed. The fact that the toponymy studies began relatively earlier demonstrates that it is perceived as a seperate branch of scientific and academic study in Russia. It also proves that toponymy studies and its applications have been built on strong and institutive foundations. In this regard, the research methods in Russian toponymy and their applicabilities are the subject matter of this study. The aim of this study is to prove that toponymy studies in Russia have been conducted systematically pursuant to certain rules. Another aim of this study is to create resource for Turkish researchers and Turkish toponymy studies. The history of Russian toponymy, scientists and their academic studies, the research methods developed in Russian toponymy, their context and applicability are also reviewed in the study.
\end{abstract}

Structured Abstract: Toponymy has continued to develop as a separate discipline by benefiting from various disciplines such as linguistics, geography, history and sociology since the beginning of twentieth century. Formation of geographical names has always been a subject which draw attention of people immemorially. Therefore, the origin of the name, the language it belongs to, its meaning and its structure entailed a special research area and accordingly a discipline called toponymy appeared. The function of toponymy discipline is basically to analyze the names of places (toponyms) morphologically and semantically to reveal findings based on scientific and practical data. There is research in every country all over the world where toponyms are analyzed semantically and morphologically.

The toponymy studies in the Russian Toponymy studies have dated back to old times. The appearance of toponymy as an academic discipline has known to date back to 18th and 19th centuries. During those periods, academicians began to analyze toponyms independently and detail them in geographical, historical and linguistic terms.

\footnotetext{
* Bu çalışma Gazi Üniversitesi, Sosyal Bilimler Enstitüsü, Rus Dili ve Edebiyatı Anabilim Dalında tamamlanmış "Sovyet Döneminde Yeradbilim: Kuramlar ve Alan Örneklemeleri” (2018) başlıklı doktora tezinden üretilmiştir.

${ }^{* * *}$ Dr. Öğr. Üyesi. Anadolu Üniversitesi, Edebiyat Fakültesi, Rus Dili ve Edebiyatı Bölümü. Asst. Prof. Anadolu University, Faculty of Humanities, Department of Russlian Language and Literature. ORCID 0000-0003-2225-1698

sonnuraktay@gmail.com

Cite as/ Atıf: Aktay, S. (2020). Rus yeradbiliminde geliştirilen inceleme yöntemleri ve Rus toponimlerinde uygulanabilirliği. Turkish Studies - Language, 15(3), 1033-1046. https://dx.doi.org/10.47845/TurkishStudies.41720

Received/Geliş: 11 February/Şubat 2020

Accepted/Kabul: 15 September/Eylül 2020

Copyright $($ INTAC LTD, Turkey
} 
In Russia, the toponym research was started by investigating names etymologically. The meanings, historical background and the language groups of the names have led linguists to examine the names of regions. Certain methods and techniques have been developed in order to carry out more systematic research in this area. The methods enabling a systematic analysis of toponomies has partially bridged the theoretical gap in Russia. The primary methods in Russian Toponymy are as follows:

"Analyzing Toponyms in Linguistic Context" is a method developed to examine the features such as phonetics, structure and meaning of the language. In order to the understand the naming done in different ages, it is essential to analyze the linguistic features. It is primarily significant to scrutinize the linguistic features of words especially in toponymy studies of ancient periods. Researchers firstly opted for examining the sounds in the word in order to comprehend the meaning. Within that period, they carried out research by taking the languages that the local people spoke into consideration. "Philological Method" is preferred to evaluate the elements such the name used in the text, its location in the text, its necessity and the reason to choose the word in the text. "Classification Method" is one of the most frequently used methods in toponymy research. The frame of the city, lake or street name that is tackle is firstly generated via classification. For instance, according to Russian linguist V. A. Juchkevich the names are classified via: 1. Nouns reflecting the natural features of the region; 2) The names of tribes; 3) Common nouns; 4) Proper nouns; 5) Nouns from foreign languages; 5) Nouns reflecting religious and cultural norms; 6) Toponyms deriving from adjectives and nouns. Each researcher is able to employ a different method in his studies. A researcher examining a word morphologically evaluates it in terms of common nouns, proper nouns or toponyms deriving from adjectives and nouns while a researcher examining a word semantically evaluates it by taking historical, etymological and cultural context into consideration. "Comparative Method" aims to reveal the differences of the words by comparing the dialects and adstrates. "Etymological Analysis Method" enables the analysis of the origin and meaning of the word as well as the language family it belongs to. "Lexicalization Method" is defining the toponyms via language and cultural interactions of societies. Although, minorities in a region affect the toponyms, they are generally shaped thanks to the languages which the majority speak. This method clearly answers the question from which language the words come. To illustrate, in Russian toponyms adjectives such as bolshoy (big), malenkiy (small), maliy (little), verhniy (up), nizhniy (down), noviy (new), starıy (old), zapadnıy (west), vostochniy (east), severniy (north), yuzhniy (south) are added when lexicalising new words. "Comparative Historical Method" refers to historical incidents, documents and artifact for the examination of the word's origin, structure and meaning. In this method, the research looks for the toponym in historical resources and detects spelling patterns and accordingly collects information to come to a conclusion about the word's origin, structure and meaning. The same process can be carried out by comparing different resources. While this method can be employed to analyze a single toponym, it can also be utilized to research various data belonging to a certain region. "Affix Analysis Method" makes it possible to learn the influence of the people living in the region via the analysis of frequently used affixes. For example, the Russian prefix -s (with) is seen as -su in many Russian toponyms such as Suglinok $-\mathrm{s}$ glinoy (slimy), Supes - s peskom (sandy), Sumrak - s mrakom (with darkness) Sukroma, Sukromka, Sukromna - s kromkoy (with corner) or s krayem (with border). "Mapping Method" is employed to learn the previous uses of toponyms and their transcriptions. Maps are of great importance to understand the influence of the knowledge of the effect of geography on names of places. In this method, maps that are drawn in different years are compared. "Statistical Method" enables to state the data quantitatively. Stating the data quantitatively with numbers and tables enables it to summarize the research better and understand it easily. With "Restructuring Toponyms Method" it is possible to reveal the nominative cases of the word which are used differently. In this method, the toponyms with the same roots and different suffixes are analyzed to reveal the nominative form of the word. "Differences in Names and Lineage Analysis" is a method used to detect the similarities and differences between similar names found in various resources.

As a result, in this study, principal methods in Russian Toponymy are aimed to be discussed. Thanks to current academic studies and doctoral dissertations, the theoretical gaps in this field have mostly been bridged and the number of studies in this discipline has increased. With the help of different methods, the toponym analyses have been conducted systematically.

Keywords: Russian Toponymy, Russian toponyms, Toponymical Research Methods, Onomastics, Linguistics.

Öz: Yer adları eski çağlardan itibaren araştırmacıların dikkatini çeken bir konudur. Toplumların yaşadıkları yere olan merakı, onları bu konuda araştırmaya sevk ederek adların oluşumu, kökeni, yapısı, değişimi ve diğer 
halklarla olan bağlantısı gibi sorulara yöneltmiştir. Ait olduğu toplumların tarihi, yaşam tarzı, dünya görüşü ve kültürel değerlerini içinde barındıran adlarla ilgili her bir özellik yer adları için özel bir inceleme alanı gerektirmiştir. Bu sebeple yeradbilim özellikle son yıllarda farklı disiplinlerden beslenen ayrı bir bilim dalı olarak görülmektedir. Rusya'da yeradbilim çalışmalarının temeli kadim dönemlere dayansa da akademik anlamda XVIII-XIX. yüzyıllarda başlar. Bu süreçte araştırmaların sistemli bir şekilde yürütülebilmesi amacıyla yeradbilimde belli başlı inceleme yöntemleri geliştirilmiştir. Yeradbilim alanında yapılan bilimsel çalışmaların erken dönemde başlaması ve bilim insanlarının ayrı bir bilim dalı olarak akademik anlamda bu alana yönelmesi Rusya'da yeradbiliminin kuramsal ve uygulama bakımından sağlam temellere dayandığını göstermektedir. Bu bağlamda, Rus yeradbilimi araştırmalarında kullanılan inceleme yöntemleri ve bu yöntemlerin Rus yer adlarında uygulanabilirliği bu çalışmanın konusunu oluşturmaktadır. Çalışmanın amacı, yeradbilim incelemelerinin belli bir sistem ve kurallar çerçevesinde araştırıldığını ve sonuçlandırıldığını göstermektir. Rus yeradbiliminde geliştirilen inceleme yöntemlerinin Türk ad araştırmacıları için de bir kaynak oluşturması ve Türk yeradbilime katkı sağlaması bu çalışmanın diğer hedefidir. Çalışmada Rus yeradbiliminin tarihçesi, bu alana yön veren kuramcılar ve kaleme aldıkları akademik çalışmalar, Rus yeradbiliminde geliştirilen inceleme yöntemleri, yöntemlerin içeriği ve Rus toponimlerinde uygulanabilirliği örneklerle ele alınmıştır.

Anahtar Kelimeler: Rus yeradbilimi, Rus toponimleri, yeradbilimsel inceleme yöntemleri, adbilim, dilbilim.

\section{Giriş}

Toponim (Rus. Toponim, Alm. Toponym - Geotoponym, Fr. Toponyme, İng. Toponym place name) sözcüğü Yunanca topos (yer) ve onoma (ad) kelimesinden türemiştir ve yer adları anlamına gelir. Toponimi (Rus. toponimika, Alm. Ortsnamenkunde, Fr. Toponymie, İng. toponymy) ise yer adlarını inceleyen bilim dalıdır.

Yeradbilim (toponimi) XX. yüzyıldan itibaren dilbilim, coğrafya, tarih, sosyoloji gibi farklı bilimlerden beslenen ayrı bir bilim dalı olarak gelişimini sürdürmektedir. Coğrafi adların oluşumu kadim dönemden bu yana insanların dikkatini çeken bir mevzudur. Bu sebeple adın kökeni, ait olduğu dil, anlamı ya da yapısı gibi özellikler yer adları için özel bir inceleme alanı gerektirmiş ve yeradbilim adı altında bir bilim dalı ortaya çıkmıştır. Yeradbilimin işlevi yer adlarını morfolojik ve semantik açıdan inceleyerek bilimsel ve gerçekçi verilere dayanan bulgular ortaya koymaktır.

Yeradbilim, herhangi bir köy, şehir, ülke ya da bölgedeki yer adları üzerinde yapılan dil çalışmalarını kapsar. Her biri mensubu olduğu dilin ve milletin tarihinden, kültüründen izler taşıyan yer adlarının halk etimolojilerinden, efsanelerden arındırılması, onların köken, anlam ve gramer yapılarının ortaya çıkarılması, bu adların oluşmasında etkili olan geleneklerin belirlenmesi yeradbilimin ana konusunu oluşturur. Haritalardan ya da halklardan derlenen malzeme, araştırmalar sonucu elde edilen bilgiler ışı̆̆ında çeşitli açılardan sınıflandırılır. Böylece yer adlarının türleri, anlam ve yapı özellikleri belirlenerek araştırmaya tabi tutulan yer adlarının genel karakteri ortaya çıkarılmış olur. Elde edilen bu bilgiler, türü, anlamı ve yapısı çözülemeyen yer adlarının çözümü konusunda bir veri olarak kullanılır. Bu şekilde yer adının geçmişteki şekli, yazılışı, hangi dil kaynaklı oluşu, anlamı, veriliş sebebi gibi konular açıklığa kavuşur (Şahin, 2015: 74).

Her ülkede toponimlerin semantik ve morfolojik açıdan ele alındığı çalışmalar mevcuttur. Rus yeradbiliminde de yeradbilimsel çalışmaların temeli oldukça eskidir. Rusya'da yeradbilimin akademik bir disiplin olarak ortaya çıkışı XVIII-XIX. yüzyıllara dayanır. Bilim insanları bu dönemde yer adlarını bağımsız olarak incelemeye ve tarihsel, coğrafi, dilbilimsel açıdan detaylandırmaya başlar.

Rusya'da toponim araştırmalarına öncelikle adların etimolojik açıdan incelenmesiyle başlanmıştır. Adların anlamları, tarihsel geçmişi, hangi dil grubuna dâhil oldukları dilbilimcilerin bölge adlarını incelemelerine sebebiyet vermiştir. Toponimlerin tarihsel bakış açısıyla incelenmesi amacıyla ilk olarak 1627'de "Genel Coğrafi Çizimleri Açılama Kitabı" (Книга большому чертежу) hazırlanır. Kitapta XVI-XVII. yüzyıllarda Rusya topraklarında bulunan yer (şehir, köy), su, dağ adlarının etimolojisi, yerleşim yerlerinin birbirine olan uzaklığı, coğrafi konumu ayrıntılı olarak ve ölçümlerle verilmiştir. Ayrıca Rusya'nın komşu olduğu sınır bölgelerine de değinilmiş ve Rusya 
topraklarında yaşayan Rus olmayan etnik grupların yer adlarına olan etkileri dile getirilmiştir (Kniga Bolşomu Çerteju, 1950: 1-7). Eserde her bölge titizlikle çalışılmış ve bölgeler arası ulaşım şekilleri dikkate alınarak sayısal değerler belirtilmiştir. Bu eser, yeradbilim çalışmalarında araştırmacıların sıklıkla başvurduğu önemli kaynaklar arasındadır.

XIX. yüzyılın sonu XX. yüzyılın başında P. L. Maştakovıy, İ. A. İznoskov, A. F. Orlov, V. V. Lamanskiy, L. S. Berg, F. P. Savarenskiy gibi önemli isimler yeradbilim alanında çalışmalar yapmayı sürdürmüşlerdir. Bu dönemde farklı toplumların dil etkileşimleri konusuna sıklıkla değinen dilbilim uzmanları, budunbilim ve yeradbilim arasındaki bağlantı üzerinde durarak Fin-Ugor halkının konuştuğu Komi dili, ${ }^{1}$ Mordvin dilleri, ${ }^{2}$ Çirmiş dili, ${ }^{3}$ Udmurtça ${ }^{4}$ dillerinin etkileşimi konusunda çalışmalar yapmışlardır (Popov, 1965: 19-20).

1960’lı yıllarda Moskova, Leningrad (günümüzdeki adı Petersburg), Riga, Ulyanovsk şehirlerinde düzenlenen adbilim konferanslarıla birlikte üniversitelerin pedagoji enstitülerinde toponim araştırma grupları oluşmaya başlar. $\mathrm{Bu}$ gruplar küçük bölgeler yerine büyük semtleri araştırma sahası olarak seçerler. Bu dönemde yeradbilim çalışmaları önemli ölçüde ilerleme kaydetmiştir.

1980'li yılların sonu ve 90'ların başında Rusya'da yeradbilim komisyonları oluşturulur. Geçmiş dönemde kurulan komisyonlar günümüzde Moskova, Petersburg, Ryazan, Tambov, Lipetsk, Vladimir gibi birçok farklı şehirde faaliyetlerine devam etmektedir. Komisyonların amacı, modern çağa uygun, aynı zamanda gelenekleri yansıtan adlar oluşturmaktır. Bu çalışmalara yeradbilim, dil, tarih, coğrafya alanında uzman araştırmacılar katılmaktadır (Ryazanskaya Toponimiçeskaya Komissiya, 2012: 14).

Günümüzde bu alanda yapılan akademik çalışmalar, yüksek lisans, doktora tezleriyle kuramsal boşluklar doldurulmakta ve uygulamaya yönelik çalışmalar hız kazanmaktadır. Yeradbilimsel çalışmalara bakıldığında V. A. Nikonov, E. M. Murzayev, A. İ. Sobolevskiy, A. M. Selişçev, A. İ. Popov, O. R. Nazarevskiy, A. V. Superanskaya, E. M. Pospelov, V. D. Bondaletov, İ. A. Vorobyeva, L. L. Trube, G. P. Bondaruk, N. V. Podolskaya, V. N. Toporov, O. N. Trubaçev, A. K. Matveyev ve V. A. Juçkeviç gibi adbilim araştırmacılarının bu sahaya değerli katkılar sunduğu görülmektedir. Adı geçen bilim insanlarının geliştirdikleri inceleme yöntemleriyle yer adları analizleri sistemli bir biçimde sürdürülmektedir.

\section{Rus Yeradbilim İncelemelerinde Uygulanan Yöntemler}

Genel olarak yöntem, bir araştırmada sonuca ulaşmak için izlenen yol ya da süreci ifade eden bir kavramdır. Bir araştırmada geliştirilen bazı kurallar ve aşamaları doğru bir biçimde uygulayarak gerçekçi sonuçlara ulaşılabilir. Yeradbilim araştırmalarında da tıpkı diğer bilim dallarında olduğu gibi geliştirilen belli başlı inceleme yöntemleri vardır. Bu yöntemlerle yer adlarının içeriği, anlamı, semantik ve morfolojik yapısı ortaya çıkarılır. Her bilim insanının kullandığı yöntem farklı olsa da geliştirilen bu inceleme yöntemleri yer adlarının farklı yönden ele alınmasına olanak tanımaktadır. Rus yer adları incelemelerinde uygulanan temel yöntemler şunlardır:

\footnotetext{
${ }^{1}$ Rusya'nın kuzeydoğu Avrupa bölgesinde yaşayan Komiler tarafından konuşulan, Ural dil ailesine ait Perm dil grubu içinde kabul edilen eklemeli dil.

${ }^{2}$ Ural dil ailesine mensup Erzya dili ve Moksha dili bu gruba girmektedir. Mordovya ve Tatristan bölgelerinde yaşayan halkların konuştukları dil.

${ }^{3}$ Çirmişler Vetluga ve Vyatkı nehirleri arasında Volga'nın batı kolu tarafına yerleşmiş, Rusya'da yaşayan

Fin-Ugor halklarından biridir. Halk arasında Çirmiş dili konuşulmaktadır. Dil yapısı olarak Mordvin diline benzemektedir. Halkın ayıcı özellikleri kadınların kıyafetlerinde kullanılan süslemeler, atlar için kullanılan başlıklar, bronz, demir, gümüş ve altından yapılan boyun süslemeleridir. Bkz. G.A. Arhipov, "Mariytsı IX-XI vv. K voprosu o proıshojdenii naroda" (1973), Mariyskoye knijnoe izdatelstvo.

${ }^{4}$ Rusya'nın Udmurtya ve çevresinde yaşayan Udmurtlar tarafından konuşulan, Ural dil ailesine ait Perm dil grubu içinde kabul edilen eklemeli dil.
} 


\subsection{Adların Dil Bağlamında İncelenmesi (Языковая атрибуция собранного ономастического материлала)}

Bir bölgede farklı çağlarda yapılan adlandırmaların kaynağına inebilmek için öncelikle yapılaması gereken bölgede konuşulan diller hakkında bilgi toplamaktır. Sözcüğün dilsel özelliklerine inmeden kökenini bulmak neredeyse imkansızdır. Dolayısıyla, toponim adlandırmalarında o bölgede yaşayan halkların dil özellikleri büyük önem taşır. Adlandırma yapılırken dilin fonetiği, yapısı, anlamı gibi nitelikler göz önünde bulundurulur. Özellikle kadim dönem yer adları incelemelerinde sözcüğün dilsel özelliklerini ele almak öncelikli aşamalardandır. Araştırmacılar, sözcügün ne anlama geldiğini kavrayabilmek amacıyla ilk olarak sözcükteki sesleri inceleme yoluna gitmiştir. Bu süreçte bölgede yaşayan halkların konuştuğu dili göz önünde bulundurarak incelemeler yürütülmüştür. Örneğin, Ulyanovsk, Kuybişev, Penza şehirlerinin doğu kesimi, Tataristan ve Çuvaşistan’ı kapsayan Orta Volga boyu yer adlarında Fin-Ugor, Türk-Tatar ve Slav adları kullanılmıştır. Tataristan'da ve Çuvaşistan'da Türk-Tatar adları fazladır. Burada Şeşma, Nurma, Sulça, Sorma gibi büyük çay adları Fin-Ugor; Çeremşan, Samara çay adları Türk; Liponka, Kamenka, Rjavka adları ise Rus kökenlidir. Bu bölgedeki Fin-Ugor dil grubuna giren toponimlerde -nar, -ner, -ener, -ley, -lay: (Anner, Şanar, Kenner, Şejener, Ojener, Lepley, Eremoley); Türk-Tatar adlarında -ll, -la (Karmalı, Şirşala, Zirekli, Naratlı) eklerinin kullanıldığı görülmektedir. Aynı zamanda Tatar toponimlerinde elga (çay), kül (göl), saz (bataklık) terimleri de kullanılmaktadır. Karamalı-Elga, Taşlıkul, Ulukul toponimleri örnek verilebilir. Aşağı Volga boyuna bakıldığında bu bölgeye Saratov, Volgograd (eski adı Tsaritsın), Astrahan şehirleri dâhildir. Bölgedeki toponimler Türk, Fars ve Slav kökenlidir. Türk kökenli toponimlerden bazıları şunlardır: Balanda, Yeruslan çayı, Baskunçık gölü, Saratov (Sarı dağ), Astrahan (Hacitarkan), Tsaritsın (Sarı su) vb. (Yusifov ve Kerimov, 2017: 122). Rusya'nın batısında bulunan Kaliningrad şehrinin toponimleri diğer şehirlerden kısmen ayrılır. Bu alan II. Dünya Savaş1 sonrasında Rusya'ya dâhil edilmiştir. O döneme kadar Almanca adlar sayı bakımından üstündür. Ancak kadim dönem adların Slav kökenli olduğu görülmektedir. Savaştan sonra bölgede Kaliningrad, Bagrationovsk, Kutuzuvo, Sovyetsk, Pionerskaya, Gvardeysk, Geroskoye, Slavnoye gibi yeni adlar ortaya çıkmıştır. Bu yöntemi kullanırken özellikle o bölge için hazırlanmış coğrafi metinler, belgeler ve haritalardan yararlanilır.

\subsection{Metinbilimsel Yöntem (Текстологический анализ)}

Metindilbilimsel yöntemle metinde kullanılan ad, adın seçilme sebebi, gerekliliği gibi unsurlar ele alınır. Ad incelemeleri yapılırken özellikle eski metinlerde kullanılan dil üzerinde çalışmalar yürütülür. Bir toplumun dilini bilmek, tarihi araştırmalar için yeterli değildir. Dille birlikte kullanılan yazının da bilinmesi gerekmektedir. Bu süreçte eski yazıların okunmasını sağlayan, yazıları tür ve şekil bakımından inceleyen bir bilim dalı olan paleografiden yararlanılır. Bu şekilde metinde kullanılan adların hangi döneme ait olduğuna dair ipuçları elde edilmiş olur. Paleografların, bir metindeki el yazısından, yazının hangi dönemde ve nerede kullanıldığını saptamaları, eski metinleri çözümleme yöntemlerinden biridir. Eski yazının yazılmış olduğu malzemenin türüne göre, yazının kullanıldığ bölgeyi ya da insan topluluğunu saptayarak da metin çözümleme yoluna gidilebilir. Bir başka çözümleme yöntemi de, yazıcıların el yazıları arasındaki özgünlüğünü ayırt etmektir. Bu da belgelerin hangi dönemde yazıldığını belirlemeye yarar.

\subsection{Sinıflandırma Yöntemi (Классификация имен)}

Sınıflandırma herhangi bir çalışmanın temelini oluşturan önemli aşamalardan biridir. Toponim incelemelerinde farklı sınıflandırma türleri mevcuttur. Örneğin, Rus dilbilimci V. A. Juçkeviç’in yer adları alanında yaptığı araştırmaların temelini etimolojik ölçütler oluşturur. Juçkeviç’in sınıflandırma biçimi şu şekildedir;

1. Bölgenin tabiat özelliklerini yansıtan;

2. Kavim adlarından oluşan;

3. Cins isimlerden oluşan; 
4. Özel adlardan oluşan;

5. Yabancı dilden geçen;

6. Din ve kült kavramlarını yansıtan;

7. Sifat ve isimden türeyen yer adları (Yevseyeva, 2014: 63).

Sözcük-anlam ilişkisine göre yapılan dilbilimsel sınıflandırmalar en yaygın ve yer adları çözümlemelerinde en sık başvurulan yöntemler arasındadır. Dilbilimci V. N. Toporov, semantik analizlerin dilin tarihini ve bölgeyi öğrenebilmek için en güvenilir yollardan biri olduğunu belirtmiştir. Yazara göre, sözcük-anlam sınıflandırması yer adlarının etimolojik analizlerinin devamı niteliğindedir ve yer adlarının anlamı, dili, tarihçesi, coğrafi konumu, kültürel etkenleri gözler önüne serilir. Toponimleri tarihi açıdan inceleyen Seliş̧̧ev, yer adlarını sözcük-anlam sınıflandırması bağlamında şu şekilde gruplandırır:

1) Sıfat ve isimden türeyen yer adları Çyornaya Gryaz (Kara çamur), Sivtsev Vrajek (Sıvtsev çukuru);

2) İki isimden türeyen yer adları (Bor-les (iğne yapraklılar ormanı), Pole-gusli (pole: tarla, gusli: Rusların geleneksel telli çalgı aleti);

3) Gorod (şehir) sözcüğüyle birlikte kullanılan yer adları (Kitaygorod (Çin şehri), Slavgorod (Slav şehri) (Bondaletov, 2012: 186).

Her araştırmacı farklı tip sınıflandırma yöntemi kullanabilmektedir. Yer adını morfolojik açıdan ele alan bir araştırmacı, sözcüğü cins isim, özel isim, sıfat ya da isimden türeyen yer adı bağlamında değerlendirirken, semantik açıdan yapılan incelemelerde sözcüğün tarihi, etimolojisi ve kültürel etmenler ön plana çıkmaktadır. Örneğin, Çeçenskiy (Çeçenistan), Tümenskiy (Tümen oblastı), Şirinkiy rayon (Şira aymağı), Sibirskiy (Sibirya) yer adlarından türeyen soyadlarına; Tatarinov (Tatar), Arapov (Arap), Çerkasov (Çerkes), Bolgarskiy (Bulgar), Kazakov (Kazak) ise millet ya da kavim adlarıyla bağlantılı soyadlarına örnektir (Karabulatova, 2000: 98).

Genel olarak toponim sınıflandırmalarının: a) dilbilimsel sınıflandırma (yapısal, morfolojik, semantik, etimolojik) b) dilbilimsel olmayan sınıflandırma (sosyolojik, tarihsel, ideolojik, coğrafi, kültürel) olarak iki ana başlık altında toplanarak ve her bir ana başlığı kendi içinde alt başlıklarla tasnif ederek mümkün olacağ 1 sonucunu elde etmek mümkündür.

\subsection{Karşılaştırma Yöntemi (Сопоставительный метод)}

Adbilim çalışmalarına konu olan adbilimcil birimler ${ }^{5}$, belirli kurallar ve ad verme gelenekleri çerçevesinde ortaya çıkmış adlardır. Bu nedenle, herhangi bir ad araştırılırken söz konusu adı da ortaya çıkaran geleneğin ve kuralların gün yüzüne çıkarılması önem arz etmektedir. Bunu gerçekleştirmek için, incelemeye tabi tutulan ad, kadim ve çağdaş dönemde kullanılan benzerleriyle karşılaştırılmalıdır. Bu yaklaşım, araştırmanın yaptığı incelemeyi, ulaştığı sonucu sorgulamasına yol açacağından, araştırmacı gerçekçi bir sonuca ulaşıncaya kadar karşılaştırma işlemine devam edecektir. Karşılaştırma yönteminde ad, dilin diğer lehçeleri ve komşu dillerin verileriyle karşılaştırılır (Şahin, 2015: 27). Örneğin, Yauza nehri Moskova bölgesinde bulunmaktadır. Smolensk bölgesinde aynı adı taşıyan başka bir nehir daha vardır. Litvanya'daki Auzas, Auzets nehri, Auzu bataklığı ve Auzi çayırı karşılaştırıldığında bütün sözcüklerin aynı köke sahip olduğu ve genel olarak su adlandırmalarında kullanıldığı görülmektedir (Pashalov, 2014: 28).

\subsection{Etimolojik Analiz Yöntemi (Этимологический анализ)}

Etimolojik analiz yöntemi araştırmacıların en yaygın kullandığı yöntemlerdendir. Sözcüğün kökeni, anlamı ya da hangi dil grubuna girdiği adın anlamını öğrenme sürecinde önem teşkil

\footnotetext{
${ }^{5}$ Rus. Onomastiçeskaya (onimiçeskaya) leksema: Adı meydana getiren sözcüklerdeki her bir sembol için kullanılan tanımdır.
} 
etmektedir. Etimolojik çözümlemeler aynı köke sahip diğer adların çözümlenebilmesi için de ipucu niteliğindedir.

Avrupa'nın en uzun nehri olan Volga nehrinden örnek verecek olursak adın birkaç kez değiştiği çeşitli kaynaklarda yer almaktadır. Yunan filozof ve coğrafyacı Ptolemaios II. yüzyılda Volga'nın aşağı tarafı için $R a$ adını kullanmıştır. Bu adın Sanskritçedeki srava (akıntı) sözcüğü ile bağlantılı olduğu düşünülmektedir. Volga nehrinin eski adı ise İdil'dir. İdil Türkçe bir sözcüktür ve Tatarca büyük nehir anlamına gelir. Kaynaklarda İdil adının İdel, Etel, Atal biçimiyle kullanıldığı da olmuştur (Pospelov, 2008: 143). Yapılan analizler doğrultusunda Volga sözcüğünün etimolojisine dair farklı varsayımların öne sürüldüğü görülmektedir. Bu konuda ortak bir görüş birliği sağlanamamıştır. Sözcüğün; 1) Slavca vlaga (nem, rutubet); Eski Slavca volglly (nemli, sslak, rutubetli); 2) Estonca valge (beyaz, açık renkli); 3) Baltık dili grubu ilg (uzun) sözcüklerinden türemiş olabileceği düşünülmektedir (Nikonov, 1966: 87).

Etimolojik analiz yöntemi yeradbilimde olduğu gibi adbilimin diğer kolu olan kişiadbilim araştırmalarında da sıklıkla kullanılmaktadır. Orta Asya Türk lehçeleri üzerinde çalışan Rus Türkolog ve dilbilimci N. A. Baskakov'un “Türk Kökenli Rus Soyadları” (Русские фамилии Тюркского происхождения) çalışmasında geçen Rus soyadlarının etimolojik analizlerinden örnekler sunmak mümkündür. Örneğin, Bulgakov Rus tarihinin en eski ve en yaygın kullanılan soyadlarındandır. Bulgakov soyadı Türk kökenli bulgay sözcüğüyle ilişkilidir. Bu sözcük Türkçe bulya-bylya fiilinden türemiştir. Fiilden türemiş isim olarak kabul edilebilir. İlk anlamı karıştırmak, çalkalamak, ikinci anlamı bulandırmak, üçüncü anlamı ise iteklemek, vurmak şeklindedir. Bulya fiili 1) karıştırmak, bulandirmak, yaratmak, yellenmek; 2) elini sallamak; 3) bulamak anlamlarına gelir. Ayn1 fiil Kırgızcada 1) yellemek (elini sallamak), basmak; 2) bulamak; 3) bulaştırmak; Kazakçada 1) karıştırmak, 2) bulamak, 3) yăga bastırmak; Altaycada 1) karıştırmak, çalkalamak, 2) değiştirmek anlamlarına gelmektedir. Diğer Türk dillerinde de benzer anlamı taşımaktadır. Bulya fiiline $-g$ soneki geldiğinde bulyag sözcüğü ortaya çıkar. Heyecanlı ve kibirli gibi iki anlam kazanan sözcük Kazakçada işsiz güçsüz dolaşan anlamındadır. Türkçe fiil olan bulya, Rus konuşma diline özel isim şeklinde girmiştir. Bulya: rahatsız, heyecanll; Bulgatnik, Bulgaten: telaşlı adam; Bulgaçnıy, Bulgatit, Bulgaçit, Bulamutit: rahatsız etmek, heyecanlandırmak, kipırdatmak, bulandirmak, saptırmak anlamlarında kullanılmaktadır. Sonuç olarak Bulgakov soyadı bulyag sözcügünden türemiştir. Kibirli, kararsız anlamlarına geldiği gibi işsiz, aylak anlamında da kullanılmaktadır (Baskakov, 1997: 37). Kurakin soyadının etimolojisine bakıldığında benzer bir durum söz konusudur. Kurakin, gurag-guryak sözcüklerinden türemiştir ve Türk kökenlidir. Gurag-guryak sözcüğü çağdaş Türk lehçelerinde iki anlamda kullanılmaktadır. Gura-gurya: 1) parçalardan oluşmuş, eklenmiş, 2) toplamak, 3) bulmamak, öldürmek; Kazakçada 1) çeşitli parçalardan dikmek, toplamak, süpürmek; Kırgızcada 1) parçalardan oluşmak, 2) biriktirmek, toplamak anlamlarına gelmektedir. Gur fiilinin anlamlarına bakıldığında Kazakçada koymak, yerleştirmek, iteklemek, kurmak anlamlarına geldiği gibi Kırgızcada da koymak, dikmek, teşkil etmek, yaratmak anlamlarını taşımaktadır. Türk dillerinde Gurag-gurya sözcükleri aynı zamanda kuru, kurumuş, sararmak, ağarmak, çürümek, cansızlaşmak anlamlarına gelmektedir. Sözcügün bu anlamdaki kullanımına Türk dillerinin birçoğunda rastlanmaktadır. Sonuç olarak Kurakin soyadı ve onun eski biçimi olan Kuraka lakabı kuru, kurumuş anlamına gelen sözcüklerle ilgilidir. Adın temelinde Türkçe bir sözcük olan gurag yatmaktadır. Insanlarla iliş̧kilerinde tutarsız, boş tavırlar sergileyen ve cömert olmayan kişi anlamlarına gelmektedir (Baskakov, 1997: 37). Turgenyev soyadı da Türk kökenlidir. Turgenyev kökünde turgen sözcügünü muhafaza etmektedir ve Moğolca hızlı, acele eden anlamlarına gelmektedir. Bu sözcük günümüzde de Sibirya Türk ağızlarında bu anlamıyla kullanılmaktadır. Daşkov, Uşakov, Buturlin, Mamonov, Sablukov, Tarbeyev, Aksakov, Talişin, Apraksin, Karsakov, Saltıkov, Balaşov, Emirov, Konakov, Ahmatov, Kozakov, Telegin Türk kökenli soyadlarından bazılarıdır. 


\subsection{Sözcük Türetme Yöntemi (Словообразовательный анализ)}

Herhangi bir bölgede kullanılan toponimler yapı ve anlam olarak çeşitlilik gösterir. Yer adı uzun yıllar içinde farklı biçimlere bürünebilir, bölge halkının ya da farklı halkların dillerinden etkilenerek değişime uğrayabilir. Dil canlı bir varlıktır, bu nedenle toponimler değişime ve etkileşime her daim açıktır. Özellikle değişik dillerin konuşulduğu bir bölgede toponimlerin telaffuz edilme şekli değişkenlik gösterebilmektedir. Bu şekilde bir sözcükten yeni sözcük türeyebilmekte ve adlar zamanla ilk kullanımından bambaşka bir şekle bürünebilmektedir.

Sözcük türetme yöntemi toponimlerin toplumların dil (yapı, fonetik) ve kültürel etkileşimiyle farklı biçimlerde tanımlanmasıdır. Toponimler üzerinde bölgede azınlık olarak yaşayan etnik grupların etkisi olsa da, adlar genellikle çoğunluğun konuştuğu dile göre biçimlenir.

Toponimlerde sözcük türetme yöntemi A. A. Ageyeva, F. Bezlay, L. L. Gumetskaya, M. S. Zayçenkova, V. V. Lopatin, G. A. Lıkov, E. M. Murzayev, V. A. Nikonov, S. Rospond, A. M. Selişçev, G. P. Smolitskaya, A. İ. Sobolevskiy, A. V. Superanskaya, V. N. Toporov, O. İ. Trubaçev, İ. S. Uluhanov, N. A. Yanko-Trinitskaya gibi adbilim araştırmacıları tarafından incelenerek, bölge adları üzerinden uygulamalar yapılmıştır.

Rusya'nın Başkurdistan Cumhuriyeti'ne bağlı Birsk (Börö) şehrinden örnek verecek olursak bölgede yaşayan halkların çoğunlukta Ruslardan oluşmasına rağmen Slav kökenli toponimlerin yanı sira Novobiktimirovo (Novo-yeni, bik-bey, timir-Timur), Yantuzovo (yantuz-yeni) gibi Türk kökenli toponimlerin de kullanıldığı görülmektedir. Toponimlerde yeni sözcükler türetilirken malo- (az), novo- (yeni), staro- (eski) takılarının kullanıldığı göze çarpmaktadır: Malo-gvardeyskiy (muhafız asker), Malo-gonçarnıy (çömlek, balçıktan yapılan), Novo-desyatkino (on, onluk), Novo-kulçibayevo (Kolsobay-şahıs adı), Novo-biktimirovo (Bey Timur), Novo-nikolskoye (Nikolay), Staro-petrovo (Petro), Novo-stroyki (yap1) vb.

Birsk şehrinde bolşoy (büyük), malenkiy (küçük), mally (küçük, az), verhniy (yukarı), nijniy (aşağı), novıy (yeni), starıy (eski), zapadnıy (batı), vostoçnıy (doğu), severnıy (kuzey), yujnıy (güney) sıfatlarından türetilen toponimler de oldukça fazladır. Sokak adlandırmalarında adın başına farklı sıfatlar getirilerek yeni adlar türetilmiştir: Bolşaya Naberejnaya (büyük rıhtım), Malaya Naberejnaya (küçük rıhtım), ulitsı Verhnyaya - Nijnyaya (yukarı-aşağı sokağı), ulitsı Novaya - Staraya (yeni-eski sokağı), ulitsı Severnaya - Yujnaya (Kuzey-Güney sokağı) vb. (Tuguzbayeva ve Suleymanova: 2012: 226-227).

\subsection{Karşılaştırmalı Tarihsel Yöntem (Сравнительно-исторический метод)}

Tarihsel yöntem, çözümü amaçlanan adın ya da adların bir geçmişi olduğundan hareketle, onun kökeni, yapısı ve anlamını geçmişte yaşanan olaylarda, dolayısıyla tarihi eserlerde ve belgelerde aramadır. Karşılaştırmalı tarihsel yöntem uygulamasında, yer adı, içinde bulunması muhtemel olan kaynaklarda araştırılır; bu kaynaklardaki imla özellikleri tespit edilir. Kaynaklarda bu ad çerçevesinde verilen bilgiler toplanır ve elde edilen bilgiler değerlendirilerek adın hangi dilde oluştuğu, kökü, yapısı ve anlamı konusunda bir sonuca varılır. Aynı işlem farklı kaynaklar karşılaştıılarak gerçekleştirilir. $\mathrm{Bu}$ yöntem tek bir adın araştırılması sırasında uygulanabileceği gibi, bir bölgeye ait çok sayıdaki malzemenin araştırılması sırasında da uygulanabilir. Bu yöntemle adların, kaynağı, kökeni, yapısı ve anlamı konusunda oldukça gerçekçi sonuçlara ulaşmak mümkündür (Şahin, 2015: 26). Yeradbilim araştırmalarının özellikle bu yöntem esasında yapıldığı bilinmektedir. Bu yöntem özellikle tarihçiler tarafindan tercih edilmektedir.

\subsection{Ek Analizi Yöntemi (Формантный анализ)}

Ekler, toponimlerde geçen takıların yapısını gösteren işaretlerdir. Genellikle sözcügüü sonundaki takılar bu yöntemin sınırını belirlemektedir. Bu yöntem yer adlarının yapısal bakımdan incelenmesine olanak tanıdığı için araştırma sonunda tekrarlanan sonekler, önekler ve sözcügün kökü ortaya çıkarılır. 
Toponimlerde kullanılan eklerin yer adları incelemelerinde kullanılması yöntemi son dönemde araştırmacılar tarafından tercih edilmektedir. $\mathrm{Bu}$ araştırma yöntemiyle toponimlerde tekrarlanan eklerin kullanım sebebi ve bölgede yaşayan halkın dil üzerindeki etkisi öğrenilmektedir. N. V. Podolskaya toponimleri biçimlendiren eklerle ilgili olarak şu yorumu getirir:

"Her dilin kendine özgü coğrafi terminolojisi vardır. Toponimlerde kullanilan bu terminoloji dlşında yer adlarına verilen ekler bulunur. Ekler tek başına bir anlam ifade etmese de toponimlerle birlikte yeni bir anlam kazanır. Halkların kendi dili ve kültürü ile oluşan bu ekler toponimlere canlllı kazandirmaktadır" (Podolskaya, 1964: 87).

XIX. yüzyıl Rus dilbilimcilerinden A. H. Vostokov'un Rus toponimlerinde geçen eklerin kullanımına yönelik çıkarımları oldukça gerçekçidir. Vostokov, Rus hidronimlerinde (su adları) kullanılan -ra: Peçora, Ijora; -ga: Pinega, Onega; -ma: Klyazma, Vyazma ekleriyle yapılan örneklere ilk dikkat çeken kişilerdendir. Rusya'da X-XII. yüzyıllarda çok sık tekrar edilen -vl eki XII. yüzyıldan sonra popülerliğini kaybetmiştir. Bunların yanı sıra kadim Rus yer adlarında $-s u$ ekinin kullanıldığı görülmektedir. $-S u$ ön eki toponimlerde birliktelik anlamı taşımaktadır. Rusçadaki $-s$ (ile) edatı Rus toponimlerinde $-s u$ şeklinde karşımıza çıkmaktadır. Örneğin, Suglinok $-s$ glinoy (killi, balçıklı), Supes - s peskom (kumlu), Sumrak - s mrakom (karanlıkla), Sukroma, Sukromka, Sukromna - s kromkoy (kenarla) ya da s krayem (sınırla) anlamını taşımaktadır (Basik, 2006: 29).

Sovyetler Birliği döneminden örnek verecek olursak bu dönemde sonu -gorsk takısı ile biten şehir ve köy adları göze çarpar. Rusya'da şehir ve köylerde -gorsk takısı toponimlerin tarihini yansitması açısından önem arz etmektedir. Bu sözcüğün Rusçada coğrafi bir terim olan gora (dağ) sözcüğünden türediği düşünülse de Rus dilbilimci ve yeradbilimci A. V. Superanskaya -gorsk takısının anlam olarak Rusçadaki dağ sözcüğü ile ilgisi olmadığı belirtmiştir. Araştırmacıya göre bu sözcük kendi içinde gorod (şehir) anlamını barındırır. Başka bir deyişle - gorsk takısı Rusça duvar, çit anlamına gelen ograda sözcügünün tahrif edilmiş biçimidir (Superanskaya, 2014: 155). SSCB döneminde sonu - gorsk takısıyla biten toponimlerden bazıları şunlardır: Çerno-gorsk (Siyah şehir), Ugle-gorsk (Kömür şehri), Soli-gorsk (Tuz şehri), Jelezno-gorsk (Demir şehri), Boksito-gorsk (Boksit şehri), Nefte-gorsk (Petrol şehri), Vişnevo-gorsk (Vişne şehri), Volno-gorsk (Dalga şehri), Visokogorsk (Yüksek şehir), Dalne-gorsk (Uzak şehir), Divno-gorsk (Güzel şehir), Zeleno-gorsk (Yeşil şehir), Krasno-gorsk (Kızıl şehir), Lenino-gorsk (Lenin şehri), Magnito-gorsk (Mıknatıs şehri), Snejno-gorsk (Kar şehri) vb. (Trube, 2005: 61-66). Görüldüğü gibi -gorsk takısı sözcüğün anlamına bakılmaksızın birçok yer adında kullanılmıştır.

Rus adbilim uzmanı V. A. Nikonov Rus toponimlerinin büyük oranda soneklerden oluştuğunu ifade eder. Nikonov'a göre Rus toponimleri \%94 soneklerden oluşmaktadır (Curayeva, 2014: 72). Rusça sözcüklerin yanı sıra yabancı kökenli sözcüklere de $-s k,-k a,-c ̧ i k,-k a n$ gibi bazı takılar verilerek Rus dil yapısına uygun hale getirilmiştir.

\subsection{Haritalama Yöntemi (Ономастическое картографирование)}

Yer adları incelemelerinde başvurulan öncül kaynakların başında haritalar gelir. Haritalar özel içeriğe ve amaca yönelik hazırlanmaktadır. Adları haritalama işi geçmişten beri kullanılan yöntemlerden biridir. Rus yeradbilimine ve haritacılık alanına uzun yıllar katkı sağlamış olan E. M. Pospelov, Rus yer adlarının haritaya dökülmesi işine önem gösteren araştırmacıların başında gelir. Araştırmacı, toponim incelemelerinde haritaların önemini her zaman savunmuş ve çalışmalarında haritalara, hazırlanışlarına ve yer adları incelemelerindeki kullanımlarına ağırlık vermiştir. Haritalar aracıllı̆ıyla Rusya toponimlerinin geçmişteki kullanımları, transkripsiyonu gibi birçok bilgiye rahatlıkla ulaşılabileceğini belirtmiştir. Harita oluşturma, kullanılan terminoloji, coğrafi terimlerin karşılaştırılması ve Rusçaya çevrilmesi gibi haritacılıkla bağlı bütün konular Pospelov'un çalışma alanını oluşturmaktadır. Pospelov'un da ifade ettiği gibi haritalar halkların yaşadıkları coğrafyayı öğrenmeleri, dilin yer adlarına etkisini görmeleri bakımından önem arz etmektedir. Tarihi eserlerin içeriğine her araştırmacı hâkim olamayabilir. Bu durumda tarihi eserlere başvuramayan araştırmacı 
haritalar üzerinden sözcüğün yapısı, anlamı, dil özellikleri gibi birçok bilgiye ulaşabilmektedir. Haritalama yöntemi kullanılırken farklı yıllarda hazırlanmış çizimler karşılaştırılarak ele alınmalıdır. $\mathrm{Bu}$ şekilde değişimin boyutu kolaylıkla ortaya çıkacaktır.

Toponim çözümlemeleri beraberinde yerel etimolojinin de oluşmasına olanak tanır. Bu şekilde sözcüklerin yerel dilde hangi anlamda kullanıldığ daha kolay anlaşılmaktadır. Örneğin, coğrafi adlarda yerel terimler sıklıkla kullanılmıştır. Örneğin, Rusçadaki voda (su), reka (nehir), ozero (göl), rodnik (kaynak), holm (tepe), gora (dağ), hrebet (sırt, dik), seleniye (köy), gorod (şehir) sözcükleri Rusya toponimlerinde kullanılan terimlerdir. Türk dilli halkların kullandığ yerel coğrafi terimlerden de örnek vermek gerekirse dag (Kopetdag), bulak (Altan-Bulak), su (Aksu), kum (Karakum), kul (Issık$K u l) v b$. sıklıkla kullanılan terimlerdendir. Her dile özgü var olan yerel coğrafi terimlerin toponimlerde kullanılması sözcüğün hangi dilde kullanıldığını öğrenmek açısından belirleyicidir. Yerel coğrafi terimler aracılığıyla sözcüklerin morfolojisi yani isim, sıfat ya da sayı durumunda kullanıldığı kolaylıkla anlaşılmaktadır. Bu bağlamda bölgede yaşayan halk, konuşulan dil ve yerel coğrafi terimlerin öğrenilmesi oldukça önemlidir.

\subsection{Adların İstatistiği (Инвентаризация ономастического материала)}

İstatistik yöntemi, elde edilen bulguları nicelik açısından ifade etmeyi sağlar. Yapılan bir araştırmayı sayısal verilerle ifade etme ve tablolar oluşturarak görselleştirme, çalışmanın özetlenerek daha kolay anlaşılmasını sağlamaktadır. Yeradbilim araştırmalarında istatistik yönteminden çok sık yararlanılmaktadır. Birçok adbilim çalışması, derlenen çok sayıda adbilimcil birim çerçevesinde yapılmakta ve tür incelemesi leksik-semantik inceleme ve gramer incelemesi sirasinda adlar tekrar tekrar ele alınmaktadır. Sürekli tekrarlardan kaçınmak amacıyla hazırlanan istatistiki tablolar, hem araştırmacının elde ettiği sonuçları kolaylıkla ifade etmesine hem de okuyucunun konuyu daha rahat algılamasına imkân tanımaktadır. Bir bölgedeki toponim araştırmalarına başlamadan önce o sahada bulunan köy, akarsu, göl ya da dağ adlarının listesi oluşturulur. Liste oluşturulduktan sonra yer adlarının yapısı karşılaştırılarak incelenir. Liste oluşturmak çalışmanın sistemli bir biçimde ilerlemesini de sağlayacaktır. Örneğin, Krasnodar bölgesinin Tihoretskiy şehri yer adlarının son ekleri ile ilgili çıkarımlara bakıldığında -ov \%8,6; $-k a \% 3,5 ;-s k 32,9$ iken -in ile biten yer adına rastlanmamaktadır. Yine Krasnodar bölgesinin Pavlovskiy şehrinde - ov \%4,6; -in \%2,3; -sk \%38,6; in \%2,6 oranındadır (Trubaçev, 2009: 21). Yüzde olarak verilen oranlar dışında kesin sayıların verildiği sonuçlar da mevcuttur. Tula bölgesinin güneybatısında bulunan Oktyabrskiy, Volovskiy, Yefremovskiy, Kamenskiy, Safonovskiy, Kurkinskiy şehirlerinde sonu -ov, -in ile biten toponimlerin sayıs1 138, sonu $-k a$ ile bitenlerin sayısı ise 257'dir. Tula bölgesinin kuzeyinde bulunan Aleksinskiy, Zaokskiy, Ivankovskiy, Şkiryatovskiy, Mordvesskiy şehirlerinde ise sonu -ov, -in ile biten toponimlerin sayıs1 400 iken - $k a$ ile biten yer adları 112 tanedir (Trubaçev, 2009: 21).

Örneklerden de görüldüğü üzere elde edilen bulguların en açık sunumu bu yöntemle sağlanır diyebiliriz. İstatistik yöntemi için örnek oluşturabilecek bir tablo aşağıda yer almaktadır. 
Tablo 1: Rus Toponimlerinin Son Eklere Göre Yüzde Oranları

\begin{tabular}{|c|c|c|c|c|c|c|c|}
\hline Bölge, Şehir & $-o v$ & - in & $-\mathbf{k a}$ & $-\mathbf{s k}$ & - içi & - iha & - yata \\
\hline $\begin{array}{l}\text { İvanovskaya } \\
\text { (Batı Bölgesi) } \\
\text { Alkovskiy } \\
\text { İlinskiy }\end{array}$ & 49,2 & 18,4 & 6,9 & 3,9 & - & 3,9 & - \\
\hline $\begin{array}{l}\text { Vladimirskaya } \\
\text { (Batı Bölgesi) } \\
\text { Pokrovskiy } \\
\text { Kirjaçskiy }\end{array}$ & $\begin{array}{l}49,2 \\
45,5\end{array}$ & $\begin{array}{l}20,0 \\
22,7\end{array}$ & $\begin{array}{l}3,1 \\
3,0\end{array}$ & $\begin{array}{l}- \\
7,6\end{array}$ & $\begin{array}{l}- \\
-\end{array}$ & $\begin{array}{l}- \\
-\end{array}$ & - \\
\hline $\begin{array}{l}\text { Tula } \\
\text { (Güneydoğu } \\
\text { Bölgesi) } \\
\text { Epifanskiy } \\
\text { Kurkinskiy }\end{array}$ & $\begin{array}{l}15,5 \\
13,5\end{array}$ & $\begin{array}{l}8,8 \\
4,5\end{array}$ & $\begin{array}{l}38,7 \\
36,5\end{array}$ & $\begin{array}{l}6,1 \\
16,8\end{array}$ & $\begin{array}{l}- \\
-\end{array}$ & $\begin{array}{l}- \\
- \\
\end{array}$ & $\begin{array}{l}- \\
-\end{array}$ \\
\hline $\begin{array}{l}\text { Penza } \\
\text { Ternovskiy } \\
\text { Kondolskiy }\end{array}$ & $\begin{array}{l}1,9 \\
4,6\end{array}$ & $2, \overline{6}$ & $\begin{array}{l}3,5 \\
2,3\end{array}$ & $\begin{array}{l}32,9 \\
38,6\end{array}$ & $\begin{array}{l}- \\
-\end{array}$ & $\begin{array}{l}- \\
-\end{array}$ & - \\
\hline
\end{tabular}

Kaynak: Nikonov, V. A. (2011). Vvedeniye v toponimiku. s. 78.

Tabloda belli başı Rus şehirlerinde sonu $-o v,-i n,-k a,-s k,-i c ̧ i,-i h a$, -yata takısı ile biten yer adlarının kullanım oranı verilmiştir. Benzer bir istatistiksel çalışma sayı ya da yüzde oranları belirtilerek her bölgede uygulanabilir. Bu tür istatistiksel veriler, elde edilen bulguların kesinliğini arttırmaktadır.

Kişiadbilim incelemelerinde de bu yönteme sıklıkla başvurulur. Örneğin, Arhangelsk bölgesinde sonu $-o v,-y e v,-i n$ ya da $-o y,-i y,-\imath y$ ile biten soyadlarını inceleyen bir araştırmacı elde ettiği bulguları yüzdeler halinde ve sayısal verilerle tablolara dökmek durumundadır. Rus adbilimci V. A. Nikonov'un "Soyadların Coğrafyası" (География фамилий) başlıklı eseri bu yöntem için iyi bir örnektir. Rus soyadlarında geçen coğrafi adları inceleyen araştırmacı her konuyu istatiksel verilerle sonuçlandırmıştır. Örneğin Rusya'nın kuzeyinde kullanılan soyadlarını tarihçe ve anlam bakımından ele alan araştırmacı şu sonuca ulaşmıştır: Popov soyadı Arhangelsk bölgesinde 216, Zauralye'de 68, Tula'da 14; Kuznetsov soyadr Arhangelsk'te 35, Zauralye'de 48, Tula'da 96; Karelskiy soyad ise Arhangelsk'te 88 kişi tarafından kullanılıyorken Zauralye ve Tula'da tek kişide dahi yoktur. Ya da sonu - skiy ile biten soyadlarına bakıldığında XIX. yüzyılda çok popülerken XIX. yüzyılın sonunda çoğunluklu olarak köylüler arasında yaygınlaşmıştır. 1897 yılı verilerine göre Şenkurskiy soyadı 3315; Yedemskiy soyadı 459; Ponejskiy 26; Bubnovskiy 227 kişi tarafından kullanılmıştır. Karelskiy soyadı ise Arhangelsk ve Holmogorskiy bölgesinde 2164 kişide mevcuttur (Nikonov, 2008: 69).

\subsection{Adların Yeniden Yapılandırılması (Реконструкция имен и их форм)}

Adbilimde kişi adlarının yeniden yapılandırılması değişik formda kullanılan adların yalın halini ortaya çıkarmaya yöneliktir. Bu yöntemde farklı kaynaklarda kökü aynı ancak son eki değişkenlik gösteren adlar toplanır ve adın yalın halini ortaya çıkarmaya yönelik araştırma yürütülür. Adlar yalın, tamlayan, belirtme, yönelme durumu gibi ismin farklı hallerinde kullanılabilmektedir.

Kilise takvimlerinde adlar ismin tamlayan durumunda kullanılırken, bazı kadın adlarının babaya, eşe ve erkek kardeşe göre değişkenlik gösterdiği görülmektedir. Erkek adları üzerinden yapılan kadın adlandırmalarında İvanyaya, Yanevaya şeklinde adlar ortaya çıkmaktadır. Yani erkek adından kadın adları oluşturulmuştur. Bu durumda araştırmacı adın temeline yönelmektedir. Örneğin, Ísayev (soyadı) İsayeviç (baba adı) kaynaklarda farklı şekillerde geçmektedir: a) Rus kilise takvimi 
adlandırmalarında ${ }^{6} \dot{I}_{s a i y a}$ İsaia, günlük hayatta $\dot{I}_{s a y}$; b) Müslümanlarda $\dot{I} s a$ olarak kullanılmaktadır. Eski metinlerde $\dot{I}_{s a y k a}$ olarak geçen adın Rusçadaki İsay ve Müslümanların kullandığı İsa adıyla ilişkili olduğu düşünülebilir. İsmin tamlayan durumunda kullanılan ve Rus kilise takviminde geçen Kotka adının yalın durumu ise Kotok ve Kotko şeklindedir. Dolayısıyla bir sözcüğün farklı durumlarda yalın halde kullanımı da olabilmektedir. Bu yöntem için toponimlerden oluşan antroponimler örnek verilebilir. Örneğin, Meretskiy soyadının Mereka, Mereta, Meretsa, Mereki, Meretı, Meretsı, Merekovo, Meretovo, Meretsovo, Meretka, Meretska, Mera yer adlarından meydana gelmiş olabileceği ihtimali yüksektir (Kobrin, 2008: 226).

\subsection{Adlardaki Farklılıklar ve Soy Analizi (Дифференциальный и генетический анализ)}

Toponimlerin şahıs isimleriyle adlandırılması her zaman karşılaşılabilecek olağan bir durumdur. Şahıs adlarıyla oluşturulan yer adları yapısal olarak farklı biçimlerde karşımıza çıkabilmektedir. Bu yöntem, kaynaklarda geçen benzer adların genetiğini, birbiriyle olan yakınlığını ve farklılıklarını ortaya çıkarmak amacıyla kullanılmaktadır. Örneğin, Maksut - Magsud, Evgeniya Evdeniya adları görünüşte oldukça benzerdir. Bu inceleme yöntemiyle adların aynı ya da farklı adlar olduğu ve kullanım farkları araştırılır. İgor Alayı Destanı'nda (Слово о полку Игореве) geçen Ovlur adının Rus ismi Lavr veya Lovur adıyla olan yakınlığını ortaya çıkarmak ya da Guriy, Gurey, Gur, Ogurey adlarının hangi soya ait olduğunu öğrenmek bu yöntemin konusudur (Superanskaya, Staltmane, Podolskaya, Sultanov, 2009: 204).

Bu yöntem sadece şahıs adlarındaki farklılığı değil aynı zamanda herhangi bir yer adıyla ilgili değişik çağrışımları da ele alır. Bir yer sadece haritada verilen haliyle adlandırılmayabilir. Bölge halkı tarafından farklı biçimlerde tanımlanabilmekte ya da seçilen sözcükler o adı çağrıştırabilmektedir. Dağ, tepe, orman, göl gibi terimler anlamsal olarak net bilgiler barındırdığı için bu terimler farklı çağrışımlar sağlamamaktadır. Özel adlarda bu farklılıklarla ve çağrışımsal ifadelerle daha sık karşılaşılır. Örneğin Rusya'da birçok köyün merkezden uzak, kullanılmayan yerleri için köyün adı yerine Vıgnanka (ayrı, terkedilen) sözcüğü kullanılmaktadır. Benzer şekilde bataklık alanlar için de Bagna (bolota - bataklık) şeklinde adlandırılan bölgeler bulunmaktadır.

\section{Sonuc}

Rusya'da yeradbilim araştırmaları akademik anlamda XIX. yüzyılda başlasa da, yer adları incelemelerinin daha eski dönemlere dayandığı görülmektedir. Yer adları öncelikle etimolojik açıdan ele alınarak adların kökeni, tarihi ve bölgede yaşayan halklar arasında bağlantılar kurularak araştırılmıştır. Bilim insanlarının yeradbilime yönelmesiyle bu alan bilimsellik kazanmış ve yapılan araştırmalar sistemli bir şekilde sürdürülmüştür.

Rus bilim insanlarından A. H. Vostokov (1781-1864), N. İ. Nadejdin (1804-1856), M. A. Kastren (1813-1852), V. A. Nikonov (1904-1988), E. M. Murzayev (1908-1988), A. İ. Sobolevskiy (1856-1929), A. M. Selişçev (1886-1942), A. İ. Popov (1899-1973), A. V. Superanskaya (1929-2013), E. M. Pospelov (1923-2007), V. D. Bondaletov (1928-2018), V. N. Toporov (1928-2005), O. N. Trubaçev (1930-2002), A. K. Matveyev (1926-2010), V. A. Juçkeviç (1915-1985), N. V. Podolskaya (1927-1995) gibi değerli araştırmacılar yeradbilim alanında uzmanlaşmış ve bu bilim dalının gelişimine yön vermişlerdir. Yeradbilimin bir bilim dalı olarak ilerlemesi yönünde akademik çalışmalar yaparak Rus toponimlerini analiz etmiş ve dönemin tarihine işık tutmuşlardır. Aynı zamanda yer adlarının sistemli ve bilimsel temellere dayanarak araştırılması yönünde belli başlı inceleme yöntemleri geliştirmişlerdir.

\footnotetext{
${ }^{6}$ Üzerinde azizleri anma günlerinin gösterildiği, aynı zamanda bu kutsal şahsiyetlerin adlarının yazılı olduğu Ortodoks takvimidir. Bkz. Aktay, Ş. (2019). Rus Antroponimisi: Kuramlar ve Uygulamalar. Ankara: Doktora Tezi. Gazi Üniversitesi, Sosyal Bilimler Enstitüsü, Rus Dili ve Edebiyatı Anabilim Dalı. s.132.
} 
$\mathrm{Bu}$ çalışmada maddeler halinde verilen yöntemler, yeradbilim araştırmalarının belli bir sistematik düzen içerisinde yürütüldüğünü göstermektedir. Bu bağlamda yer adları sınıflandırmaları $a$ ) sözcük-anlam b) yapısal-dilbilgisel c) etimolojik d) sosyal-tarihsel e) ideolojik f) kültürbilimsel açıdan yapılırken, adbilim incelemelerinde adların dil bağlamında incelenmesi, metinbilimsel yöntem, sinfflandırma yöntemi, karşılaştırma yöntemi, etimolojik analiz yöntemi, sözcük türetme yöntemi, karşılaş̧tırmalı tarihsel yöntem, ek analizi yöntemi, haritalama yöntemi, adların istatistiği, adların yeniden yapılandırılmasl, adlardaki farklılıklar ve soy analizi gibi farklı birçok yöntemin kullanıldığı tespit edilmiştir. Yeradbilim uzmanları tarafından geliştirilen bu yöntemler adbilim araştırmalarında sıkça kullanılarak, adların yapı ve anlam bakımından incelenmesine ve anlamlandırılmasına ışık tutmaktadır.

\section{Kaynakça}

Aktay, S. (2019). Rus Antroponimisi: Kuramlar ve Uygulamalar. Ankara: Doktora Tezi. Gazi Üniversitesi, Sosyal Bilimler Enstitüsü, Rus Dili ve Edebiyatı Anabilim Dalı.

Arhipov, G. A. (1973). Mariytsı IX-XI vv. K Voprosu o Prolshojdenii Naroda. Mariyskoye knijnoe izdatelstvo.

Basik, S. N. (2006). Obşçaya Toponimika. Minsk: Uçebnoe posobiye dlya studentov geografiçeskogo fakulteta. BGU.

Baskakov, N. A. (1997). Türk Kökenli Rus Soyadları. Çev. S. Kazımoğlu, Türk Dil Kurumu Yayınları.

Bondaletov, V. D. (2012). Russkaya Onomastika. URSS.

Curayeva, Ş. (2014). Toponimı v Pamyatnikah Pismennosti $17 \mathrm{~V}$. Dissertatsiya na soiskaniye akademiçeskoy stepeni magistra. Termez.

Karabulatova, İ. (2000). O Modelyah Vospriyatiya Toponimi Tyumenskoy Oblasti Sovremennımi Nositelyami Russkogo Yazıka. Szlav Filologiya Tanszek, 97-105.

Kniga Bolşomu Çerteju. (1950). Podgotovka k peçati i redaktsiya K. N. Serbina, Nauk.

Kobrin, V. B. (2008). Opriçnina. Genealogiya. Antroponimika. RGGU.

Nikonov V. A. (1966). Kratkiy Toponimiçeskiy Slovar. Mısl.

Nikonov, V. A. (2008). Geografiya Familiy. URSS.

Nikonov, V. A. (2011). Vvedeniye v Toponimiku. LKİ.

Pashalov, A. P. (2014). Udivitelnaya Etimologiya. ENAS.

Podolskaya, N. V. (1964). Kakuyu İnformatsiyu Nesyot Toponim. V kn. Printsipı toponimiki, 87-99.

Popov, A. İ. (1965). Geografiçeskiye Nazvaniya - Vvedeniye v Toponimiku. Nauka.

Pospelov, E. M. (2008). Geografiçeskiye Nazvaniya Rossiii - Toponimiçeskiy Slovar. Astrel.

Ryazanskaya Toponimiçeskaya Komissiya. (2012). Pod red. N. A. Bulıçyov, Ryazan.

Superanskaya, A. V., Staltmane, V. E., Podolskaya, N. V., Sultanov, A. H. (2009). Teoriya i Metodika Onomastiçeskih İssledovaniy. URSS.

Şahin, İ. (2015). Adbilim (Çerçeve, Terim, Yöntem ve Sinıflandırmalarıyla). Pegem Akademi.

Trubaçev, O. N. (2009). Trudı Po Etimologii. Slovo. İstoriya. Kultura.Rukopisnıye pamyatniki drevney rusi. 
Trube, L. L. (2005). Nazvaniya Gorodov i Poselkov s Formantom - gorsk (gorskiy). Uralskiy Federalnıy universitet, 61-66.

Tuguzbayeva, O. V. ve Suleymanova, A. K. (2012). Strukturno-slovoobrazovatelniye Osobennosti Toponimov G. Birska i Birskogo Rayona. Başkurdistan: Vestnik Başkirskogo universiteta, 225-228.

Yevseyeva, O. S. (2014). Vopros o Klassifikatsii Toponimov Russko-Belorusskogo Prigraniçya. Vestnik MGOU, Seriya Russkaya Filologiya, 61-63.

Yusifov, Y. ve Kerimov, S. (2017). Toponiminin Esasları Üzerine Bir İnceleme. (Çev: S. Yavuz). ASOS yayınları. 